\section{Morphological Changes of Condyles and Helkimo Clinical Dysfunction Index in Patients Treated with Herbst - Orthodontic Appliance}

Luís Antônio de Arruda Aidar ${ }^{1}$, Márcio Abrahão ${ }^{2}$, Hélio K. Yamashita ${ }^{3}$, Gladys Cristina Dominguez ${ }^{4}$

\author{
'Department of Orthodontics, \\ UNISANTA - Santa Cecília \\ University, Santos, SP, Brazil \\ ${ }^{2}$ Department of Otorhinolaryngology, \\ Paulista School of Medicine, \\ UNIFESP - Federal University of \\ São Paulo, São Paulo, SP, Brazil \\ ${ }^{3}$ Department Imaging Diagnostic, \\ Paulista School of Medicine, \\ UNIFESP - Federal University of \\ São Paulo, São Paulo, SP, Brazil \\ ${ }^{4}$ Department of Orthodontics, School \\ of Dentistry, USP - University of \\ São Paulo, São Paulo, SP, Brazil \\ Correspondence: Luís Antônio \\ de Arruda Aidar, Rua Luiz \\ Suplicy 35, 11055-330 Santos, \\ SP, Brasil. Tel: +55-13-3223- \\ 5689. Fax: +55-13-3223-5689. \\ e-mail: luisaidar@uol.com.br
}

\author{
Key Words: magnetic resonance, \\ Angle class II malocclusion, \\ orthodontic appliance, \\ temporomandibular joint disorders.
}

\section{Introduction}

Class II malocclusion associated with mandibular retrognathism may be treated using orthopedic functional appliances in the first phase of treatment to advance the mandible and to improve its anteroposterior adjustment during growth (1-9). In the second phase of treatment, fixed orthodontic appliances are used to refine occlusion $(1,9)$. The responses of the temporomandibular joints (TMJs) treated using this method are controversial, which has led to the conduction of studies using the three-dimensional finite element method (10) as well as analyses in groups of experimental animals (11) or humans beings (1-9).

Functional analyses of the masticatory system $(12,13)$ by means of clinical evaluations, combined with morphological changes in the TMJs diagnosed using imaging tests, have been included in some studies $(1,6-9)$ to elucidate the effects of treatment using the Herbst appliance.

Studies using panoramic radiographs, computer tomography (CT) scanning and transpharyngeal exposure (6) aimed at evaluating TMJs after Herbst therapy. However, radiographs and CT scans are of limited value in imaging the condyle cartilage. On the other hand, magnetic resonance imaging $(\mathrm{MRI})$ is noninvasive, does not require ionizing radiation for image acquisition and provides direct visualization of the disc and joint structures (14-19).

Investigations using $\mathrm{MRI}$ have identified the mechanisms of TMJ remodeling in patients treated with the Herbst appliance $(7,8)$. However, in isolated cases, some authors have reported structural bone changes in different condyle morphologies after such treatments $(20,21)$.

This prospective longitudinal study assessed possible changes in the condyle morphology of TMJs and calculated the Helkimo clinical dysfunction index (CDI) in adolescents with Class II, Division 1 mandibular retrognathism who were treated with the Herbst appliance followed by fixed orthodontic appliances.

\section{Material and Methods}

This study was approved by the Ethics Committee of the Federal University of São Paulo (Process \#0428/09), and all patients or their guardians signed an informed consent form.

In this study, 32 consecutively white adolescents (16 male and 16 female) were treated using a Herbst appliance for 12 months (phase I). Mean pre-treatment age was 12.8 \pm 1.2 years (range: 10.9 to 15.8 years). Immediately after completing phase I, 23 of the 32 adolescents ( 13 male and 10 female) continued treatment with a fixed orthodontic appliance (phase II) using pre-adjusted $0.022 \times 0.028$-inch brackets (mean phase II duration $=2.2 \pm 0.9$ years). Phases I and II were performed by the same orthodontist.

Patients with the following characteristics were enrolled 
in the study: clinical appearance of a retrognathic mandible with ANB angle greater than 4 degrees; Angle Class II, Division 1 malocclusion with permanent dentition; mean overjet of $8.6 \pm 2.1 \mathrm{~mm}$ (range: 5 to $13 \mathrm{~mm}$ ); maximum of skeletal pubertal growth peak evaluated by the hand and wrist X-rays (22).

The first phase consisted of treatment with a modified Herbst appliance (metal crowns, bands, upper Hyrax expander and lower lingual arch - Fig. 1). As transversal maxillary deficiency frequently occurs in Class II malocclusions (23), rapid maxillary expansion was performed during the first 2 weeks after placement of the Herbst appliance (one turn on the first day and half a turn on subsequent days until clinical correction was achieved (1)).

The mandible was advanced up to $6 \mathrm{~mm}$ at the beginning of the treatment. When necessary, supplementary advances of 2 to $3 \mathrm{~mm}$ were achieved in the third month. In all 32 adolescents, treatment with the Herbst appliance $(1,7,8)$ resulted in Class I or overcorrected Class I dental arch relationships.
In phase II, an Interlandi headgear (IHG) was used during leveling to reduce possible loss of anchorage on maxillary molars, which had been moved distally during treatment with the Herbst appliance (3). At the end of phase II, all 23 patients showed good occlusal adjustment and functional occlusion.

MRI of the right (R) and left (L) TMJs with the mouth closed (MC) and mouth open (MO) were taken at four time points during treatment: immediately before the beginning of phase I $\left(T_{1}\right), 8-10$ weeks after Herbst appliance placement $\left(T_{2}\right)$, at the end of phase I $\left(T_{3}\right)$ and at the end of phase II $\left(T_{4}\right)$.

A Philips Gyroscan ACS-NT superconductor (Philips, The Netherlands), with magnetic field intensity of 1.5 Tesla, and bilateral TMJ surface coils were used. MRI was performed using T1-weighted (w) axial planning images; T1 TSE sagittal oblique images with closed and open mouth (TR/TE: 1300/70 ms, FOV: 16 cm, NSA: 4, Matrix: 204 x 512); T2 TSE sagittal oblique images with closed and open mouth (TR/TE: 4300/120 ms, FOV: 16 cm, NSA: 4, Matrix: $204 x$ 512); Proton density FFE sagittal oblique (TR/TE: $60 / 14$ ms, FOV: $16 \mathrm{~cm}$, NSA: 4, Matrix: $212 \times 512$ ) and T1 TSE coronal
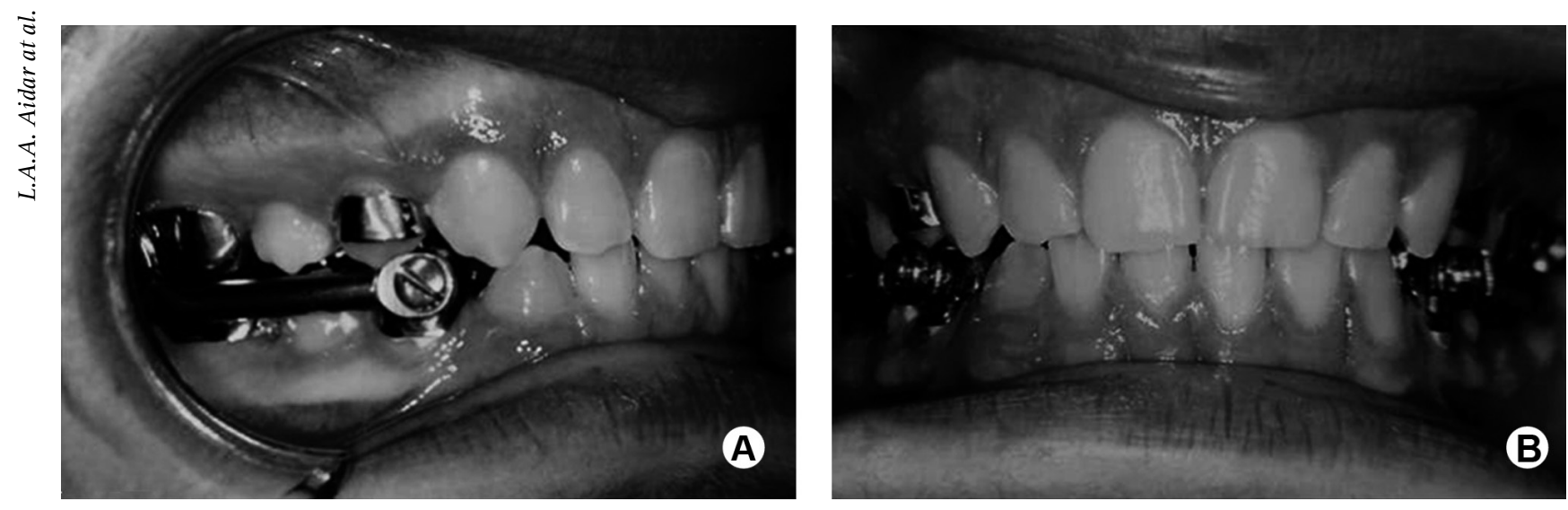

Figure 1. Right side view (A) and front view (B). Modified Herbst appliance (metal crowns, bands, upper Hyrax expander and lower lingual arc).
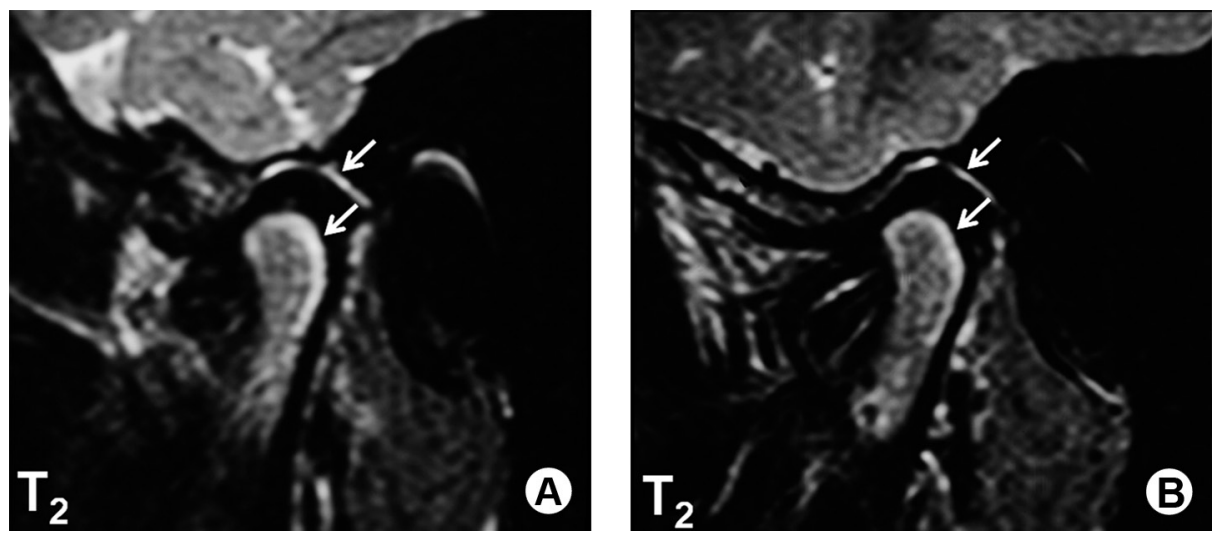

Figure 2. Patient 9 - MRls of left (A) and right (B) TMJs at $\mathrm{T}_{2}$ showed an area with hypersignal in posterior superior regions of condyles and supradiscal region, which confirmed the increase of bone remodeling in the region. 
images (TR/TE: 580/15 ms, FOV: 16 cm, NSA: 4, Matrix: 204 $x$ 512). In all images, the thickness/increment was 1.5/0.1 $\mathrm{mm}$ except in the sagittal oblique sequence in the Proton images, in which the thickness/increment was 2.8/-1.3 mm.

Parasagittal MRIs were taken perpendicularly to
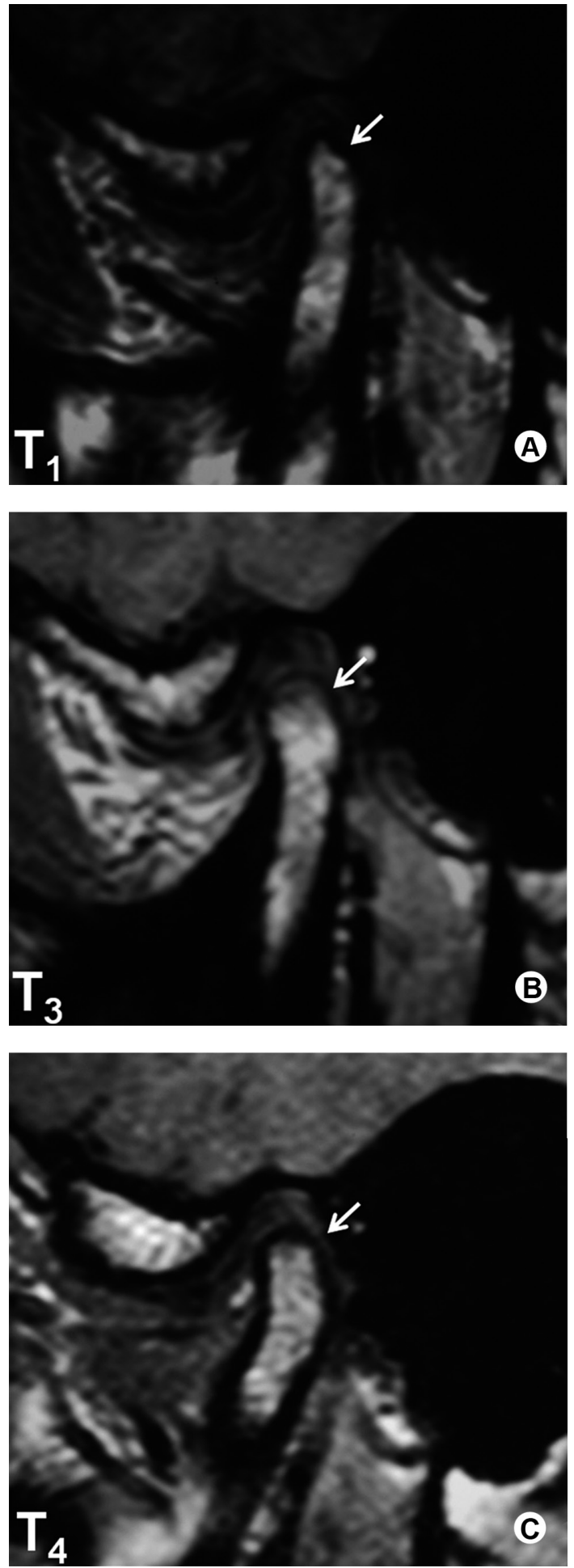

Figure 3. Patient 19 - MRls of right TMJ. There was a significant change in condyle morphology (degenerative bone disease) at $T_{1}(A)$ and it improved with treatment at $T_{3}(B)$, remaining stable when evaluated at $T_{4}(C)$. the condyle long axis and the coronal MRIs parallel to the condyle long axis. In each sequence, 16 slices were obtained (8 for each TMJ). The MRIs were examined under $2 \times$ magnification.

The MRIs were interpreted visually at the four time points $\left(T_{1}, T_{2}, T_{3}\right.$ and $\left.T_{4}\right)$ by 2 observers ('A'and ' $B$ ') using an $\mathrm{MRI}$ protocol to better define criteria for interpretation. As the 2 observers had been trained differently because of their backgrounds, they were retrained for 4 months with images not included in this study, to achieve more standardized readings. Images for this study were then interpreted 3 times by observer $A$ and once by observer $B$ (who also gave the final diagnosis). A double-blind procedure was applied. Observer A's interpretations, performed at regular 15-day intervals, were divided into preliminary and final readings. The preliminary readings consisted of one interpretation before observer A received training (pre-training) and one after training (post-training). Observer A's third reading was considered the final interpretation. Overall interobserver agreement was calculated as the proportion of the joints for which observer A's final interpretation and observer B's interpretation agreed.

At $T_{1}, T_{3}$ and $T_{4}$, condyle morphology was evaluated using the MRIs acquired at T1 (weighted parasagittal and coronal scans) in the MC position (14), and classified as normal (NL), when the articular component was rounded with a soft and intact cortex, or remodeled (R), when there was a flattening (anterior and/or superior slope, posterior - parasagittal images; contour of the cortical bone of the articular surface from lateral to medial area of the condyle - coronal images), or variation of the morphology but an intact cortex. Degenerative bone disease (DBD) was diagnosed when cavities, erosion, osteophytes or resorption were seen in the mandibular condyles (Table 1).

This study also describes findings reported in a previous publication (1) (position and shape of the joint disc at $T_{1}$, $T_{3}$ and $T_{4}$ - Table 1) for the same patients enrolled here. The purpose is to make it easier for readers to understand the possible changes in condyle morphology and Helkimo CDI (13).

Clinical exams were carried out to determine the Helkimo $C D I$ at $T_{1}, T_{3}$ and $T_{4}$. Clinical functional analysis was performed and the muscles of the stomatognathic system were palpated (24). The analysis of mandibular movements was carried out using a ruler to measure the length of the widest opening and its quality, the extension of border protrusion movements, and left and right laterotrusion. The left and right TMJs were palpated laterally and posteriorly, at rest and during movements. The presence of joint noises or crackling was also checked. The clinical findings were analyzed and scored according to the criteria (13) shown in Table 2. Next, the added score allowed classification 
into one of the four levels of dysfunction: 0 points, CDI-0 (Asymptomatic); 1-4 points, CDI-I (Mild); 5-9 points, CDI-II (Moderate); and 10-25 points, CDI-III (Severe). The clinical exams were performed by two examiners experienced in the use of the method ('A' and 'B'), both following the same protocol. The clinical evaluations in this study were performed twice by examiner "A" (10-day interval) and once by examiner " $\mathrm{B}$ " (who also gave the final diagnosis). The second evaluation by examiner "A" was considered final and was compared with the evaluation by examiner

Table 1. Condyle morphology, joint disc position and shape at $T_{1}, T_{3}$ and $T_{4}$

\begin{tabular}{|c|c|c|c|c|c|c|c|c|c|c|c|c|c|c|c|c|c|c|}
\hline \multirow{4}{*}{ Patient } & \multicolumn{6}{|c|}{ Condyle morphology } & \multicolumn{12}{|c|}{ Joint disc position } \\
\hline & \multicolumn{3}{|c|}{ Left TMJ } & \multicolumn{3}{|c|}{ Right TMJ } & \multicolumn{6}{|c|}{ Left TMJ } & \multicolumn{6}{|c|}{ Right TMJ } \\
\hline & \multirow{2}{*}{$\frac{\mathrm{T}_{1}}{\mathrm{MC}}$} & \multirow{2}{*}{$\frac{\mathrm{T}_{3}}{\mathrm{MC}}$} & \multirow{2}{*}{$\frac{\mathrm{T}_{4}}{\mathrm{MC}}$} & \multirow{2}{*}{$\frac{\mathrm{T}_{1}}{\mathrm{MC}}$} & \multirow{2}{*}{$\frac{\mathrm{T}_{3}}{\mathrm{MC}}$} & \multirow{2}{*}{$\frac{\mathrm{T}_{4}}{\mathrm{MC}}$} & \multicolumn{2}{|c|}{$\mathrm{T}_{1}$} & \multicolumn{2}{|c|}{$\mathrm{T}_{3}$} & \multicolumn{2}{|c|}{$\mathrm{T}_{4}$} & \multicolumn{2}{|c|}{$\mathrm{T}_{1}$} & \multicolumn{2}{|c|}{$\mathrm{T}_{3}$} & \multicolumn{2}{|c|}{$\mathrm{T}_{4}$} \\
\hline & & & & & & & $\mathrm{MC}$ & MO & MC & MO & $\mathrm{MC}$ & MO & MC & MO & MC & MO & $\mathrm{MC}$ & MO \\
\hline 1 & $\mathrm{NL}$ & $\mathrm{NL}$ & RPCS & $\mathrm{NL}$ & $\mathrm{NL}$ & RCS & $\mathrm{NL}$ & 1 & $\mathrm{NL}$ & 1 & $\mathrm{ADD}$ & DDWR & NL & 1 & $\mathrm{NL}$ & 1 & AMDD & DDWR \\
\hline 2 & $\mathrm{NL}$ & $\mathrm{NL}$ & $\mathrm{NL}$ & $\mathrm{NL}$ & $\mathrm{NL}$ & $\mathrm{NL}$ & $\mathrm{NL}$ & 1 & $\mathrm{NL}$ & 1 & $\mathrm{NL}$ & 1 & $\mathrm{NL}$ & 1 & $\mathrm{NL}$ & 1 & $\mathrm{NL}$ & 1 \\
\hline 3 & $\mathrm{NL}$ & $\mathrm{NL}$ & RPS & $\mathrm{NL}$ & $\mathrm{NL}$ & RPS & $\mathrm{NL}$ & 1 & $\mathrm{NL}$ & 1 & $\mathrm{NL}$ & 1 & NL & 1 & $\mathrm{NL}$ & 1 & $\mathrm{NL}$ & 1 \\
\hline 4 & $\mathrm{NL}$ & $\mathrm{NL}$ & RCS & $\mathrm{NL}$ & $\mathrm{NL}$ & RCS & LDD & 1 & LDD & 1 & LDD & 1 & NL & 1 & $\mathrm{NL}$ & 1 & $\mathrm{NL}$ & 1 \\
\hline 5 & $\mathrm{NL}$ & $\mathrm{NL}$ & $\mathrm{NL}$ & $\mathrm{NL}$ & $\mathrm{NL}$ & $\mathrm{NL}$ & MDD & 1 & MDD & 1 & MDD & 1 & MDD & 1 & MDD & 1 & MDD & 1 \\
\hline 6 & $\mathrm{NL}$ & $\mathrm{NL}$ & $\mathrm{NL}$ & $\mathrm{NL}$ & $\mathrm{NL}$ & $\mathrm{NL}$ & $\mathrm{NL}$ & 1 & $\mathrm{NL}$ & 1 & $\mathrm{NL}$ & 1 & $\mathrm{NL}$ & 1 & $\mathrm{NL}$ & 1 & $\mathrm{NL}$ & 1 \\
\hline 7 & $\mathrm{NL}$ & $\mathrm{NL}$ & $\mathrm{NL}$ & $\mathrm{NL}$ & $\mathrm{NL}$ & $\mathrm{NL}$ & $\mathrm{NL}$ & 1 & $\mathrm{NL}$ & 1 & $\mathrm{NL}$ & 1 & $\mathrm{NL}$ & 1 & $\mathrm{NL}$ & 1 & $\mathrm{NL}$ & 1 \\
\hline 8 & RPS & $\mathrm{NL}$ & RPCS & RPS & $\mathrm{NL}$ & RPCS & MDD & 1 & MDD & 1 & MDD & 1 & $\mathrm{NL}$ & 1 & $\mathrm{NL}$ & 1 & $\mathrm{NL}$ & 1 \\
\hline 9 & $\mathrm{NL}$ & $\mathrm{NL}$ & RCS & $\mathrm{NL}$ & $\mathrm{NL}$ & RPCS & $\mathrm{NL}$ & 1 & $\mathrm{NL}$ & 1 & $\mathrm{NL}$ & 1 & $\mathrm{NL}$ & 1 & $\mathrm{NL}$ & 1 & $\mathrm{NL}$ & 1 \\
\hline 10 & $\mathrm{NL}$ & $\mathrm{NL}$ & & RPS & RPS & & AMDD & DDWR & AMDD & DDWR & & & AMDD & DDWR & AMDD & DDWR & & \\
\hline 11 & $\mathrm{NL}$ & $\mathrm{NL}$ & $\mathrm{NL}$ & $\mathrm{NL}$ & $\mathrm{NL}$ & $\mathrm{NL}$ & $\mathrm{NL}$ & 1 & $\mathrm{NL}$ & 1 & ADD & DDWR & ALDD & DDWR & LDD & 1 & ALDD & DDWR \\
\hline 12 & $\mathrm{NL}$ & $\mathrm{NL}$ & & $\mathrm{NL}$ & NL & & $\mathrm{NL}$ & 1 & $\mathrm{NL}$ & 1 & & & NL & 1 & $\mathrm{NL}$ & 1 & & \\
\hline 13 & RPCS & RPCS & & RPS & RCS & & ALDD & DDWR & ALDD & DDWR & & & ADD & DDWR & $\mathrm{ADD}$ & DDWR & & \\
\hline 14 & RPS & RPS & $\mathrm{NL}$ & RPS & $\mathrm{NL}$ & RPCS & $\mathrm{NL}$ & 1 & $\mathrm{NL}$ & 1 & $\mathrm{NL}$ & 1 & $\mathrm{NL}$ & 1 & $\mathrm{NL}$ & 1 & $\mathrm{NL}$ & 1 \\
\hline 15 & RCS & RCS & & RPCS & RCS & & $\mathrm{NL}$ & 1 & $\mathrm{NL}$ & 1 & & & $\mathrm{NL}$ & 1 & $\mathrm{NL}$ & 1 & & \\
\hline 16 & RPS & $\mathrm{NL}$ & & $\mathrm{NL}$ & $\mathrm{NL}$ & & $\mathrm{NL}$ & 1 & $\mathrm{NL}$ & 1 & & & $\mathrm{NL}$ & 1 & $\mathrm{NL}$ & 1 & & \\
\hline 17 & $\mathrm{NL}$ & $\mathrm{NL}$ & & $\mathrm{NL}$ & $\mathrm{NL}$ & & $\mathrm{NL}$ & 1 & $\mathrm{NL}$ & 1 & & & NL & 1 & $\mathrm{NL}$ & 1 & & \\
\hline 18 & $\mathrm{NL}$ & RCS & RCS & $\mathrm{NL}$ & $\mathrm{NL}$ & $\mathrm{NL}$ & $\mathrm{NL}$ & 1 & $\mathrm{NL}$ & 1 & $\mathrm{NL}$ & 1 & $\mathrm{NL}$ & 1 & $\mathrm{NL}$ & 1 & $\mathrm{NL}$ & 1 \\
\hline 19 & RPCS & RPCS & RPCS & DBD & RPCS & RPCS & ALDD & DDWPR & ALDD & DDWR & ALDD & DDWR & ALDD & DDWPR & ALDD & DDWR & ALDD & DDWR \\
\hline 20 & $\mathrm{NL}$ & $\mathrm{NL}$ & $\mathrm{NL}$ & $\mathrm{NL}$ & $\mathrm{NL}$ & $\mathrm{NL}$ & $\mathrm{NL}$ & 1 & $\mathrm{NL}$ & 1 & $\mathrm{NL}$ & 1 & $\mathrm{NL}$ & 1 & $\mathrm{NL}$ & 1 & $\mathrm{NL}$ & 1 \\
\hline 21 & $\mathrm{NL}$ & $\mathrm{NL}$ & RPCS & RCS & RCS & RCS & ALDD & DDWR & ALDD & DDWR & ALDD & DDWR & NL & 1 & $\mathrm{NL}$ & 1 & $\mathrm{NL}$ & 1 \\
\hline 22 & $\mathrm{NL}$ & $\mathrm{NL}$ & & $\mathrm{NL}$ & $\mathrm{NL}$ & & $\mathrm{NL}$ & 1 & $\mathrm{NL}$ & 1 & & & NL & 1 & $\mathrm{NL}$ & 1 & & \\
\hline 23 & $\mathrm{NL}$ & $\mathrm{NL}$ & $\mathrm{NL}$ & $\mathrm{NL}$ & $\mathrm{NL}$ & $\mathrm{NL}$ & $\mathrm{NL}$ & 1 & $\mathrm{NL}$ & 1 & $\mathrm{NL}$ & 1 & $\mathrm{NL}$ & 1 & $\mathrm{NL}$ & 1 & LDD & 1 \\
\hline 24 & $\mathrm{NL}$ & $\mathrm{NL}$ & & $\mathrm{NL}$ & $\mathrm{NL}$ & & $\mathrm{NL}$ & 1 & $\mathrm{NL}$ & 1 & & & $\mathrm{NL}$ & 1 & $\mathrm{NL}$ & 1 & & \\
\hline 25 & $\mathrm{NL}$ & $\mathrm{NL}$ & $\mathrm{NL}$ & $\mathrm{NL}$ & $\mathrm{NL}$ & $\mathrm{NL}$ & MDD & 1 & MDD & 1 & MDD & 1 & MDD & 1 & MDD & 1 & MDD & 1 \\
\hline 26 & DBD & DBD & DBD & RCS & RCS & RPCS & ALDD & DDWR & ALDD & DDWR & ALDD & DDWR & AMDD & DDWPR & AMDD & DDWPR & AMDD & DDWPR \\
\hline 27 & $\mathrm{NL}$ & $\mathrm{NL}$ & RCS & $\mathrm{NL}$ & $\mathrm{NL}$ & $\mathrm{NL}$ & AMDD & DDWR & AMDD & DDWR & AMDD & DDWR & AMDD & DDWR & AMDD & DDWR & AMDD & DDWR \\
\hline 28 & $\mathrm{NL}$ & $\mathrm{NL}$ & $\mathrm{NL}$ & $\mathrm{NL}$ & $\mathrm{NL}$ & $\mathrm{NL}$ & $A D D$ & DDWR & ADD & DDWR & $A D D$ & DDWR & AMDD & DDWR & AMDD & DDWR & AMDD & DDWR \\
\hline 29 & $\mathrm{NL}$ & $\mathrm{NL}$ & $\mathrm{NL}$ & $\mathrm{NL}$ & $\mathrm{NL}$ & $\mathrm{NL}$ & $A D D$ & DDWR & $\mathrm{ADD}$ & DDWR & $A D D$ & DDWR & AMDD & DDWR & AMDD & DDWR & AMDD & DDWR \\
\hline 30 & $\mathrm{NL}$ & $\mathrm{NL}$ & & $\mathrm{NL}$ & $\mathrm{NL}$ & & $\mathrm{NL}$ & 1 & $\mathrm{NL}$ & 1 & & & NL & 1 & $\mathrm{NL}$ & 1 & & \\
\hline 31 & $\mathrm{NL}$ & RPS & RPCS & RPCS & RPCS & RPCS & $\mathrm{NL}$ & 1 & $\mathrm{NL}$ & 1 & $\mathrm{NL}$ & 1 & $\mathrm{NL}$ & 1 & $\mathrm{NL}$ & 1 & $\mathrm{NL}$ & 1 \\
\hline 32 & $\mathrm{NL}$ & $\mathrm{NL}$ & RPS & $\mathrm{NL}$ & $\mathrm{NL}$ & RPS & $\mathrm{NL}$ & 1 & $\mathrm{NL}$ & 1 & NL & 1 & NL & 1 & $\mathrm{NL}$ & 1 & $\mathrm{NL}$ & 1 \\
\hline
\end{tabular}


"B" to assess interexaminer concordance.

Intraobserver and interobserver variability was evaluated. Agreement was poor when kappa was below 0.4 , and excellent when greater than 0.75 . The nonparametric $K$ and the McNemar tests were used to evaluate concordance

\begin{tabular}{|c|c|c|c|c|c|c|c|c|c|c|c|}
\hline \multicolumn{12}{|c|}{ Joint disc shape } \\
\hline \multicolumn{6}{|c|}{ Left TMJ } & \multicolumn{6}{|c|}{ Right TMJ } \\
\hline \multicolumn{2}{|c|}{$\mathrm{T}_{1}$} & \multicolumn{2}{|c|}{$\mathrm{T}_{3}$} & \multicolumn{2}{|c|}{$\mathrm{T}_{4}$} & \multicolumn{2}{|c|}{$\mathrm{T}_{1}$} & \multicolumn{2}{|c|}{$\mathrm{T}_{3}$} & \multicolumn{2}{|c|}{$\mathrm{T}_{4}$} \\
\hline $\mathrm{MC}$ & MO & $\mathrm{MC}$ & MO & $\mathrm{MC}$ & MO & $\mathrm{MC}$ & MO & $\mathrm{MC}$ & MO & $\mathrm{MC}$ & MO \\
\hline NB & B & NB & B & NB & B & NB & B & NB & B & NB & B \\
\hline B & B & B & B & B & B & B & B & B & B & B & B \\
\hline B & B & B & B & B & B & B & B & B & B & B & B \\
\hline B & B & B & B & B & B & B & B & B & B & B & B \\
\hline B & B & B & B & NB & B & B & B & B & B & NB & B \\
\hline $\mathrm{B}$ & B & B & B & B & B & B & B & B & B & B & B \\
\hline B & B & B & B & B & B & B & B & B & B & B & B \\
\hline B & B & B & B & B & B & B & B & B & B & B & B \\
\hline $\mathrm{B}$ & B & B & B & B & B & B & B & B & B & B & B \\
\hline NB & B & NB & $\mathrm{N}$ & & & $\mathrm{NB}$ & $\mathrm{N}$ & $\mathrm{NB}$ & B & & \\
\hline B & B & NB & B & NB & B & NB & B & $\mathrm{NB}$ & B & NB & B \\
\hline B & B & B & B & & & B & B & B & B & & \\
\hline NB & B & NB & NB & & & $\mathrm{NB}$ & B & $\mathrm{NB}$ & B & & \\
\hline$B$ & B & B & B & B & B & B & B & B & B & B & B \\
\hline $\mathrm{B}$ & B & B & B & & & B & B & B & B & & \\
\hline B & B & B & B & & & B & B & B & B & & \\
\hline B & B & B & B & & & B & B & B & B & & \\
\hline B & B & B & B & B & B & B & B & B & B & B & B \\
\hline NB & NB & NB & B & NB & B & NB & NB & NB & B & NB & B \\
\hline B & B & B & B & B & B & B & B & B & B & B & B \\
\hline NB & B & NB & B & NB & B & B & B & B & B & B & B \\
\hline$B$ & B & B & B & & & B & B & B & B & & \\
\hline$B$ & B & B & B & B & B & B & B & B & B & B & B \\
\hline B & B & B & B & & & B & B & B & B & & \\
\hline B & B & B & B & B & B & B & B & B & B & B & B \\
\hline NB & B & NB & B & NB & B & NB & NB & NB & B & NB & B \\
\hline NB & B & NB & B & NB & B & NB & B & NB & B & NB & B \\
\hline NB & B & NB & B & NB & B & NB & B & NB & B & NB & B \\
\hline NB & B & NB & B & NB & NB & NB & B & NB & B & NB & NB \\
\hline$B$ & B & B & B & & & B & B & B & B & & \\
\hline$B$ & B & B & B & B & B & B & B & B & B & B & B \\
\hline NB & B & NB & B & NB & B & NB & B & $\mathrm{NB}$ & B & NB & B \\
\hline
\end{tabular}

between left and right TMJs (condyle morphology) and changes due to treatment (condyle morphology and Helkimo CDI). The level of significance was set at 5\%. To evaluate independent data at the same observation time $(2 \times 2$ tables: condyle morphology $\times$ disc position and condyle morphology $x$ disc shape), a chi-square test was used with Yates's correction for continuity. If the lowest expected frequency was below 5, the Fishers's Exact test was used $(2 \times 2$ tables: CDI categories $x$ diagnosis using MRI of joint disc position) at a 5\% level of significance.

\section{Results}

Intraobserver variability in the analysis of condyle morphology was $\mathrm{K}=0.52$ for reading 1 vs. 2 and $\mathrm{K}=0.67$ for reading 2 vs. 3. Interobserver kappa (observer A's reading 3 vs. observer B's reading) for condyle morphology $(\mathrm{k}=0.87)$ indicated excellent agreement. Intraobserver and interobserver concordance for CDI was also excellent ( $\mathrm{k}=0.94$ and $\mathrm{k}=0.84)$.

The classifications of condyle morphology with MC and position and shape of the joint disc with $\mathrm{MC}$ and $\mathrm{MO}$ at $T_{1}, T_{3}$ and $T_{4}$ are shown in Table 1 .

Comparing left and right TMJ condyle morphology at $T_{1}$, a $K$ value of $0.405(p<0.001)$ was found, with a $75.1 \%$ concordance. It was not possible to calculate Kappa for $\mathrm{T}_{3}$ and $\mathrm{T}_{4}$ (concordance of $78.1 \%$ and $69.5 \%$ ). Once substantial agreement was observed, they were pooled.

There was no association between condyle morphology (remodeled and normal) and joint disc position at $\mathrm{T}_{1}$ $(p=0.523), T_{3}(p=0.665), T_{4}(p=0.526)$ and shape at $T_{1}$ $(p=0.771), T_{3}(p=0.566), T_{4}(p=1.000)$ or between CDI categories ( 0 and $\mathrm{I})$ and the MRI diagnosis of joint disc position at $T_{1}(p=0.057), T_{3}(p=0.358)$ and $T_{4}(p=1.000)$.

\section{Condyle Morphology}

There were no changes in $55(86.0 \%), 28(60.8 \%)$ and $26(56.5 \%)$ TMJs at $\mathrm{T}_{1}-\mathrm{T}_{3}(\mathrm{p}=0.326), \mathrm{T}_{3}-\mathrm{T}_{4}(\mathrm{p}<0.05)$ and $\mathrm{T}_{1}-\mathrm{T}_{4}$ $(p<0.05)$, respectively. Changes were found in $9(14.0 \%)$, 18 (39.1\%) and 20 (43.4\%) TMJs at $\mathrm{T}_{1}-\mathrm{T}_{3}, \mathrm{~T}_{3}-\mathrm{T}_{4}$ and $\mathrm{T}_{1}-\mathrm{T}_{4}$ respectively.

\section{CDI}

There were no changes in $26(86.6 \%), 16$ (76.2\%) and $16(76.2 \%)$ patients at $\mathrm{T}_{1}-\mathrm{T}_{3} \quad(\mathrm{p}=1.000), \mathrm{T}_{3}-\mathrm{T}_{4} \quad(\mathrm{p}=1.000)$ and $T_{1}-T_{4}(p=1.000)$, respectively. There were changes in 4 $(13.3 \%), 5(23.8 \%)$ and $5(23.8 \%)$ patients at $\mathrm{T}_{1}-\mathrm{T}_{3}, \mathrm{~T}_{3}-\mathrm{T}_{4}$ and $\mathrm{T}_{1}-\mathrm{T}_{4}$, respectively.

\section{Discussion}

MRI has been shown to be efficient in detecting joint disc disorders and changes in the shape of the fossa, eminence and mandibular condyle $(14,15)$. In this study, 
Braz Dent J 24(4) 2013

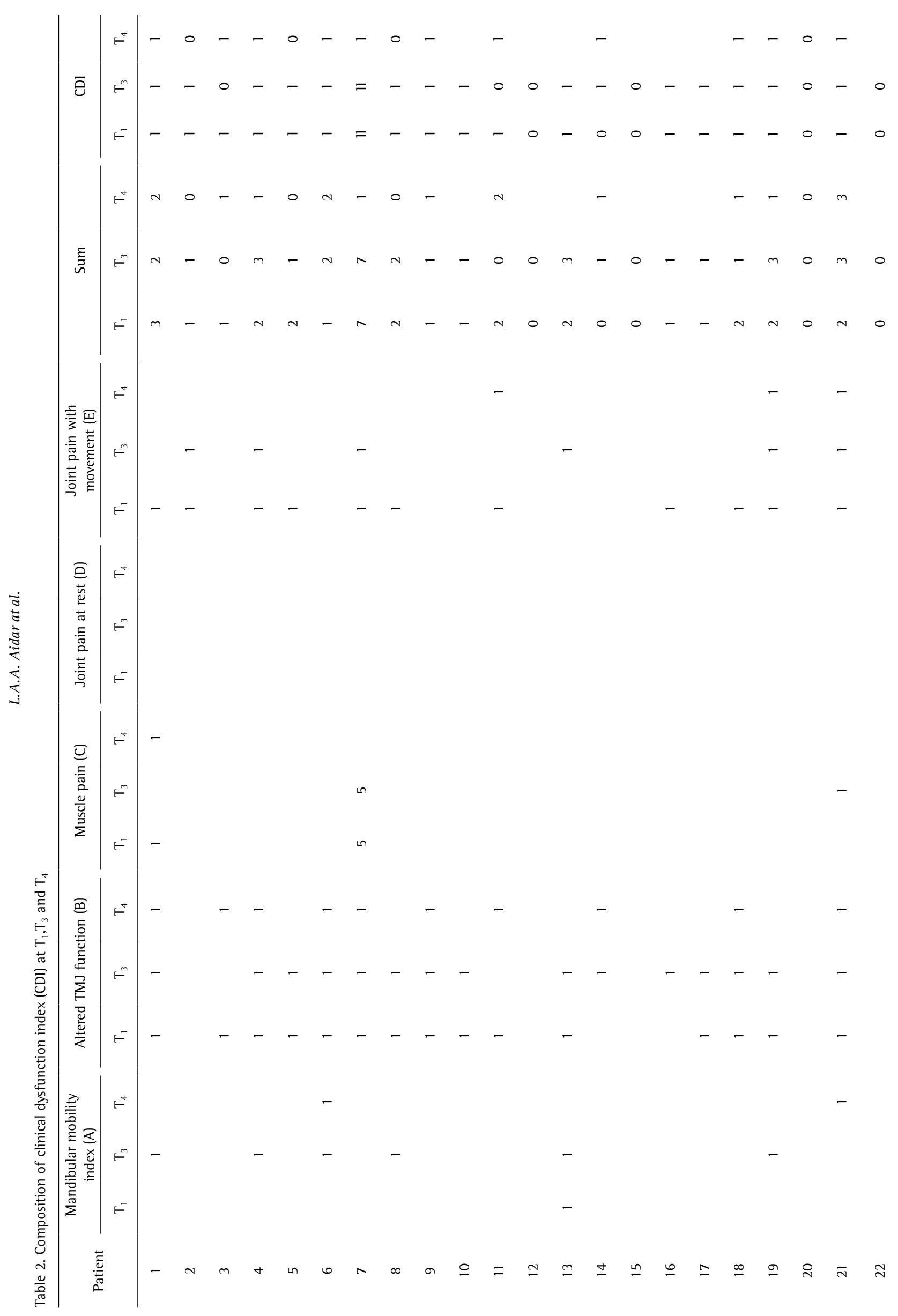




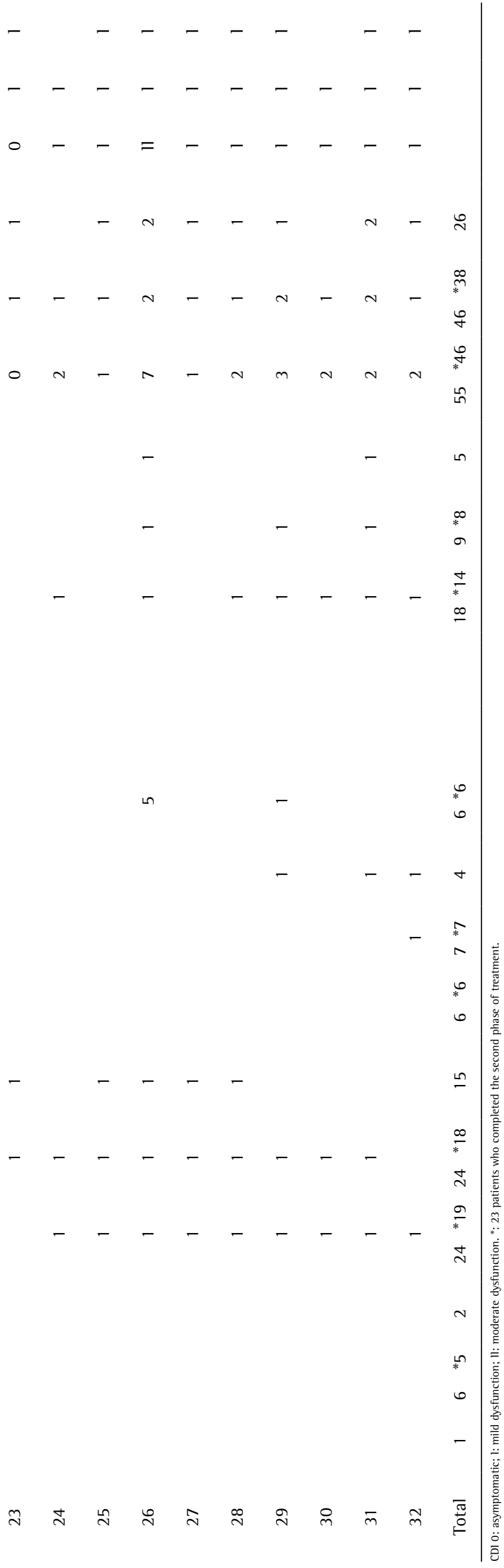

coronal images prevented false negative diagnoses when interpreting condyle morphology in 16 TMJs (9.19\%) and reinforced the diagnosis of condylar remodeling already made using the parasagittal slices in 19 TMJs (10.91\%). MRIs at $T_{2}$ showed an area with increased signal intensity (bright area) in the posterior superior region of the condyles in virtually all joints under study (Fig. 2), which confirmed the increase of bone remodeling in the region (11). Another study (5) found similar evidence in patients treated with an activator appliance. This phenomenon was not seen when a twin-block appliance was used (4), probably because the MRI sequences were different.

Our results showed that between $T_{1}$ and $T_{3}(p=0.326)$ there were no significant changes in condyle morphology in most TMJs (86.0\%). In six TMJs, condyle morphology improved at $\mathrm{T}_{3}$, regardless of position and shape of the joint disc. In case 19 (right TMJ), there was a significant change in condyle morphology (DBD) associated with anterolateral disc displacement (ALDD) and non-biconcave disc shape at $T_{1}$. Considerable improvement was observed in condyle morphology at $T_{3}$, which remained stable when evaluated at $\mathrm{T}_{4}$ (Fig. 3).

Our results are in agreement with a study that found a decreased prevalence of structural bone changes during treatment with the Herbst appliance (9), probably due to remodeling (6-9). In contrast, the left condyle in case 26 had osteophytes (DBD) associated with ALDD and a non-biconcave shape of the disc at $T_{1}$. No improvement was seen in condyle morphology at $\mathrm{T}_{3}$ or $\mathrm{T}_{4}$. In both TMJs, disc displacement was reduced, and the time of disc derangement and the degree of tissue changes in the joint components was not known.

Significant changes were found when T3 and T4 were compared $(p<0.05)$. Condyle morphology became flatter at T4 in 17 TMJs (36.9\%). In fact, mild flattening took place in joints with normal disc position and shape and in joints that already had a displaced disc at $\mathrm{T} 1$ and $\mathrm{T} 3$ or began to show disc displacement at T4. Three TMJs that had condyle morphology improvements at T3 exhibited recurrences at T4. Our results differ from those reported in a study that found a reduction in the prevalence of bone structural changes in the condyle one year after treatment with the Herbst appliance (9). In our study, patients were assessed at a mean $2.2 \pm 0.9$ years after the end of the Herbst phase, which complicates the comparison of results because of method differences. The evaluations at $\mathrm{T} 1$ and $\mathrm{T} 4$ revealed significant changes $(p<0.05)$. Condyle morphology became flatter in $18 \mathrm{TMJs}$ (39.1\%). Another study (25) found that mild condyle flattening, when associated with asymptomatic patients without internal derangement, probably has no clinical significance. That study (25) was cross-sectional and the individuals were not undergoing 
treatment, and it was not known how long those bone changes had been in place. In contrast, the participants in this study experienced condylar flattening over the course of treatment, with nearly all of the changes occurring during phase II. Changes observed could be associated with possible future problems.

In our study, patients with and without changes on MRIs are distributed similarly within the different CDI categories at all time points. This leads to the conclusion that clinical symptoms might be present even when there are no MRI findings. Disc displacement is relatively common in asymptomatic individuals (14), and the clinical diagnosis of no TMD is linked to the high rates of internal derangement detection using MRI (16). In agreement with our findings, a previous study (17) demonstrated that joint noises are not sufficient evidence of dysfunction when there are no other corroborating symptoms, although they may be found in patients with TMJ disc displacement detected using MRI. Joint pain with movement was observed in 18 of 32 patients at $T_{1}$ ( 9 of the 18 patients had disc displacement). There is a low correlation between MRI disc displacement detections and the extent of TMJ pain and dysfunction (18). At $T_{3}$, pain disappeared in 10 patients, persisted in 8 and started in 1 . At $\mathrm{T}_{4}$, that number fell to 5 out of 23 patients who already felt pain at $T_{1}$ and $T_{3}$, with the exception of patient 11 , who felt pain at $T_{1}$, which disappeared at $T_{3}$ and resumed at $T_{4}$. Patients 26 and 29 (disc displacement in both joints) were the only ones with joint pain at palpation at rest at $T_{1}$, but pain disappeared at $\mathrm{T}_{3}$ and $\mathrm{T}_{4}$. Patient 26 had DBD (left condyle), and painful joints are known to be more frequent in the presence of this type of change (15).

The analysis of muscle pain revealed that only patients 1 and 7 had scores 1 and 5 at $T_{1}$, with CDI-I and II. For patient 1 , muscle pain vanished at $T_{3}$, but dysfunction remained at CDI-I. At $\mathrm{T}_{4}$, although no change occurred in CDI-I, muscle pain resumed in association with disc displacement (left and right TMJs). No changes occurred in patient 7 at $T_{3}$; however, at $\mathrm{T}_{4}$ muscle pain disappeared, and the dysfunction index changed to CDI-I. At $\mathrm{T}_{4}$, patients 29,31 and 32 began complaining of muscle pain. Range of movement is the most evident expression of joint function (24), and its limitation may be caused by disc displacement (14). In our study, 13 patients already had disc displacement at $\mathrm{T}_{1}$, and only patient 13 had limited movements (lower than 7 $\mathrm{mm}$ ). Patient 1 , who had a well-positioned joint disc at $T_{1}$, $\mathrm{T}_{3}$ and $\mathrm{T}_{4}$ had disc displacement according to both MRIs, a likely sign of dysfunction. Patient 6 , the only one not to have a displaced disc at any time during treatment, had limited movements at $\mathrm{T}_{3}$ and $\mathrm{T}_{4}$. Our results demonstrated that limited range of movement did not characterize disc displacement in all cases. Limited lateral mandibular movements may be assigned to restricted movements caused by use of the Herbst appliance (12) and are transient. In our study, at $\mathrm{T}_{3}, 6$ patients had limited lateral movements and only patient 6 maintained limited movements at $\mathrm{T}_{4}$ i patient 21 started to have this problem at $\mathrm{T}_{4}$.

Finally, a follow-up evaluation of these patients will be important to elucidate the long-term effects of treatment with Herbst and fixed appliances on the form and function of the TMJ. In conclusion, after phase I, the condyle morphology did not change significantly. At the end of phase II, a mild flattening was seen in some condyles when patients underwent short-term evaluation. In general, no changes occurred in the clinical dysfunction index after the two phases.

\section{Resumo}

Este estudo avaliou as mudanças morfológicas nas cabeças da mandíbula das articulações temporo mandibulares (ATMs) e calculou o index de disfunção clínico de Helkimo (IDC) em adolescentes com má oclusão de Classe II Divisão1 e retrognatismo mandibular, tratados com aparelho de Herbst (fase I) e aparelho ortodôntico fixo (fase II). Trinta e dois adolescentes consecutivos passaram pela fase I e 23 completaram a fase II. As ATMs foram avaliadas qualitativamente por meio de imagem da resonância magnética (IRM) ao início do tratamento $\left(T_{1}\right)$, durante a fase I $\left(T_{2}\right)$, no final da fase I $\left(T_{3}\right)$ e no final da fase II $\left(T_{4}\right)$. 0 IDC foi calculado em $T_{1}, T_{3}$ e $T_{4}$. De $T_{1}$ a $T_{3}(p=0,326)$ não ocorreram mudanças na morfologia da cabeça da mandibula em $86,0 \%$ das ATMs. De $\mathrm{T}_{3}$ a $\mathrm{T}_{4}(\mathrm{p}<0,05)$ e $\mathrm{T}_{1}$ a $\mathrm{T}_{4}(p<0,05)$ ocorreram mudanças em $39,1 \%$ e $43,4 \%$ das cabeças das mandibulas. Não ocorreram mudanças significantes no IDC de $T_{1}$ a $T_{3}$ $\mathrm{T}_{3}$ a $\mathrm{T}_{4}$ e $\mathrm{T}_{1}$ a $\mathrm{T}_{4}$ ( $\mathrm{p}=1,000 ; 86,6 \%, 76,2 \%$ e 76,2\% concordância). Após a fase $I$, não houve praticamente mudanças na morfologia da cabeça da mandibula. Ao final da fase II, um leve aplainamento foi observado em algumas cabeças das mandibulas. Pode ser concluido que não ocorreram mudanças significantes no IDC após ambas as fases de tratamento.

\section{Acknowledgements}

The authors acknowledge the São Paulo State Research Foundation FAPESP (2009/53497-4) for the financial support.

\section{References}

1. Aidar LAA, Dominguez GC, Yamashita HK, Abrahão M. Changes in temporomandibular joint disc position and form following Herbst and fixed orthodontic treatment. Angle Orthod 2010;80:843-852.

2. Aras A, Ada E, Saracoglu H, Gezer NS, Aras I. Comparison of treatments with the Forsus fatigue resistant device in relation to skeletal maturity: a cephalometric and magnetic resonance imaging study. Am J Orthod Dentofacial Orthop 2011;140:616-625.

3. Ogeda PCR, Abrão J. Assessment of the displacement of the upper molars using the Herbst appliance. R Dental Press Ortodon Ortop Facial 2004;9:31-43.

4. Chintakanon K, Sampson W, Wilkinson T, Townsend G. A prospective study of Twin-block appliance therapy assessed by magnetic resonance imaging. Am J Orthod Dentofacial Orthop 2000;118:494-504.

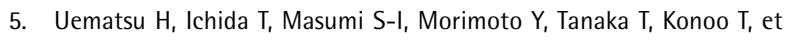
al.. Diagnostic image analyses of activator treated temporomandibular joint in growth and maturing stages. J Craniomand Practice 2002;20:254-263.

6. Paulsen HU. Morphological changes of the TMJ condyles of 100 patients treated with the Herbst appliance in the period of puberty to 
adulthood: a long-term radiographic study. Eur J Orthod 1997;19:657668.

7. Ruf $\mathrm{S}$, Pancherz H. Temporomandibular joint growth adaptation in Herbst treatment: a prospective magnetic resonance imaging and cephalometric roentgenographic study. Eur J Orthod 1998;20:375-388.

8. Ruf S, Pancherz H. Temporomandibular joint remodeling in adolescents and young adults during Herbst treatment: a prospective longitudinal magnetic resonance imaging and cephalometric radiographic investigation. Am J Orthod Dentofacial Orthop 1999;115:607-618.

9. Ruf S, Pancherz H. Does bite-jumping damage the TMJ? A prospective longitudinal clinical and MRI study of Herbst patients. Angle Orthod 2000;70:183-199.

10. Gupta A, Hazarey PV, Kharbanda OMP, Kohli VS, Gunjal A. Stress distribution in the temporomandibular joint after mandibular protraction: a 3-dimensional finite element method study. Part 2. Am J Orthod Dentofacial Orthop 2009;135:749-756.

11. Voudouris JC, Kuftinec MM. Improved clinical use of Twin-block and Herbst as a result of radiating viscoelastic tissue forces on the condyle and fossa in treatment and long-term retention: growth relativity. Am J Orthod Dentofacial Orthop 2000;117:247-266.

12. Pancherz $H$, Anehus-Pancherz $M$. The effect of continuous bite jumping with the Herbst appliance on the masticatory system: a functional analysis of treated Class II malocclusions. Eur J Orthod 1982;4:37-44.

13. Helkimo M. Studies on function and dysfunction of the masticatory system. II. Index for anamnestic and clinical dysfunction and occlusal state. Swed Dent J 1974;67:101-121.

14. Ribeiro RF, Tallents RH, Katzberg RW, Murphy WC, Moss ME, Magalhães $A C$, et al.. The prevalence of disc displacement in symptomatic and asymptomatic volunteers aged 6 to 25 years. J Orofacial Pain 1997;11:37-47

15. Oliveira JX, Rosa JA, Dutra MEP, Santos KCP, Gil C. Assessing joint effusion and bone changes of the head of the mandible in MR images of symptomatic patients. Braz Oral Res 2013;27:37-41.

16. Muhtarogullari M, Ertan AA, Demiralp B, Canay S. Correlation between clinical and magnetic resonance imaging findings in the treatment of anterior disc displacement. Int J Prosthodont 2013;26:138-142.

17. Manfredini D, Basso D, Salmaso L, Guarda-Nardini L. Temporomandibular joint click sound and magnetic resonance-depicted disk position: which relationship? J Dent 2008;36:256-260.

18. Maizlin ZV, Nutiu N, Dent PB, Vos PM, Fenton DM, Kirby JM, et al.. Displacement of the temporomandibular joint disk: correlation between clinical findings and MRI characteristics. J Can Dent Assoc 2010;76:a3.

19. Tasali N, Cubuk R, Aricak M, Ozarar M, Saydam B, Nur H, et al.. Temporomandibular joint (TMJ) pain revisited with dynamic contrastenhanced magnetic resonance imaging (DCE-MRI). Eur J Radiol 2012;81:603-608.

20. Hansen $K$, Pancherz $H$, Petersson A. Long-term effects of the Herbst appliance on the craniomandibular system with special reference to the TMJ. Eur J Orthod 1990;12:244-253.

21. Ruf S, Pancherz H. Long-term TMJ effects of Herbst treatment: a clinical and MRI study. Am J Orthod Dentofacial Orthop 1998;114:475483.

22. Björk A, Helm S. Prediction of the age of maximum pubertal growth in body height. Angle Orthod 1967;37:134-143.

23. Baratieri C, Alves Jr M, Sant'anna EF, Nojima MCG, Nojima LI. 3D Mandibular positioning after rapid maxillary expansion in Class II malocclusion. Braz Dent J 2011;22:428-434.

24. Slavicek R. Clinical and instrumental functional analysis for diagnosis and treatment plannind. Part 3 Clinical Functional Analysis. J Clin Orthod 1988;XXII:498-508.

25. Brooks SL, Westesson P-L, Eriksson L, Hansson LG, Barsotti JB. Prevalence of osseous changes in the temporomandibular joint of asymptomatic persons without internal derangement. Oral Surg Oral Med Oral Pathol 1992;73:118-122.

Received November 16, 2012 Accepted June 14, 2013 